\title{
Repetibilidade de peso de fruto e de duração do ciclo em ameixeira e pessegueiro
}

\author{
Moeses Andrigo Danner(1), Maria do Carmo Bassols Raseira(2), Simone Aparecida Zolet Sasso(1), \\ Idemir Citadin $^{(1)}$ e Silvia Scariot ${ }^{(1)}$
}

\begin{abstract}
(1)Universidade Tecnológica Federal do Paraná, Campus Pato Branco, Via do Conhecimento, Km 01, Caixa Postal 571, CEP 85503-390 Pato Branco, PR. E-mail: moesesandrigo@yahoo.com.br, iosasso@ibest.com.br, idemir@utfpr.edu.br, silviascariotto@yahoo.com.br ${ }^{(2)}$ Embrapa Clima Temperado, BR 392, Km 78, Caixa Postal 403, CEP 96001-970 Pelotas, RS. E-mail: bassols@cpact.embrapa.br
\end{abstract}

Resumo - O objetivo deste trabalho foi comparar o peso de fruto e a duração do ciclo entre cultivares de ameixeira e pessegueiro, estimar os coeficientes de repetibilidade e de determinação e o número de medições, para uma predição segura dessas características, e comparar diferentes métodos de estimação da repetibilidade. Os caracteres foram avaliados em 5 safras, em 9 cultivares de ameixeira (Prunus salicina) e 33 cultivares de pessegueiro (Prunus persica), em delineamento inteiramente casualizado. O coeficiente de repetibilidade foi estimado pelos métodos de análise de variância, componentes principais e análise estrutural. Foi observado o maior peso de fruto nas cultivares de ameixeira Harry Pickstone e Pluma 7 e na cultivar de pessegueiro Santa Áurea. A menor duração do ciclo ocorreu nas cultivares de ameixeira América, Irati e Methley e na cultivar de pessegueiro Granada. Os coeficientes de repetibilidade e de determinação foram altos para ambos os caracteres em ameixeira e pessegueiro. Não houve diferenças no coeficiente de repetibilidade entre os métodos utilizados. São necessárias de uma a três medições de peso de fruto, e de uma a duas medições da duração do ciclo, para obtenção dos valores genotípicos reais das cultivares de ameixeira e pessegueiro, respectivamente, com coeficiente de determinação de $90 \%$.

Termos para indexação: Prunus persica, Prunus salicina, genética quantitativa, seleção.

\section{Fruit weight and cycle length repeatability of plum and peach trees}

\begin{abstract}
The objective of this work was to compare fruit weight and length of cycle, among cultivars of plum and peach, besides estimating the repeatability and determination coefficients and the number of measurements, for a safe prediction of these characteristics, and to compare different methods to estimate the repeatability. The traits were evaluated in 5 productive cycle for 9 plum cultivars (Prunus salicina) and 33 peach cultivars (Prunus persica), in a completely randomized design. The repeatability coefficient was estimated by methods of analysis of variance, principal components and structural analysis. The greates fruit weight was observed for Harry Pickstone and Pluma 7 plum cultivars and for Santa Aurea peach cultivar. The shortest lenght of cycle occurred in America, Irati and Methley plum cultivars and in Granada peach cultivar. The repeatability and determination coefficients were high for both traits in plum and in peach trees. There were no differences in the repeatability coefficient estimation among the methods used. One to three measurements of fruit weight and one and two measurements of length of cycle are necessary for obtaining the real genotypic values of plum and peach cultivars, respectively, with a determination coefficient of $90 \%$.
\end{abstract}

Index terms: Prunus persica, Prunus salicina, quantitative genetics, selection.

\section{Introdução}

A ameixeira e o pessegueiro estão entre as fruteiras de clima temperado com maior número de cultivares lançadas no Brasil, originárias principalmente dos programas de melhoramento da Embrapa Clima Temperado, em Pelotas, RS, e do Instituto Agronômico (IAC), em Campinas, SP. No entanto, é necessário ainda o desenvolvimento de cultivares para melhorar a qualidade dos frutos, cujos caracteres de interesse como peso de fruto e duração do ciclo estão entre os principais para os programas de melhoramento genético no Brasil. A seleção é direcionada principalmente para genótipos com maior tamanho de fruto e ciclo mais curto, ou seja, de maturação precoce (Raseira \& Nakasu, 2001).

Pesq. agropec. bras., Brasília, v.45, n.8, p.872-878, ago. 2010 
Ao selecionar genótipos superiores para determinada característica, espera-se que ela se mantenha indefinidamente. A veracidade dessa expectativa pode ser avaliada pelo coeficiente de repetibilidade da característica, que pode ser estimado com a realização de várias medições em um mesmo indivíduo, com variações no tempo ou no espaço. O coeficiente de repetibilidade permite determinar o número de medições necessárias, para que haja eficiência na seleção fenotípica entre os genótipos e representa o valor máximo que a herdabilidade no sentido amplo pode atingir. Isso pode resultar na redução de custos e de mão de obra em programas de melhoramento genético (Cruz et al., 2004).

A demora para início da produção e a grande área requerida para o desenvolvimento de plantas perenes são entraves à instalação de experimentos com delineamentos estatísticos adequados. Isso dificulta as estimativas de parâmetros genéticos como a herdabilidade, mas não impede a estimativa da repetibilidade (Albuquerque et al., 2004).

Por sua importância no melhoramento, especialmente de plantas perenes, têm sido realizados no Brasil estudos de repetibilidade sobre várias fruteiras, como cajueiro-anão (Cavalcanti et al., 2000), açaizeiro (Oliveira \& Fernandes, 2001), aceroleira (Lopes et al., 2001), bacurizeiro (Souza et al., 2001), goiabeiraserrana (Degenhardt et al., 2002), pupunheira (Farias Neto et al., 2002), coqueiro (Farias Neto et al., 2003), mangueira (Costa, 2003), cajazeira (Soares et al., 2008), cupuaçuzeiro (Alves \& Resende, 2008), laranjeira-doce (Negreiros et al., 2008) e guaranazeiro (Nascimento Filho et al., 2009).

Albuquerque et al. (2004) estimaram, em pessegueiro, a repetibilidade de caracteres de fruto. Porém, sobre ameixeira, não foram encontrados na literatura estudos recentes de repetibilidade.

O objetivo deste trabalho foi comparar o peso de fruto e a duração do ciclo, entre cultivares de ameixeira e pessegueiro, além de estimar os coeficientes de repetibilidade e determinação e o número de medições, para uma predição segura destas características, e comparar diferentes métodos de estimação da repetibilidade.

\section{Material e Métodos}

Neste tabalho, foram utilizadas plantas a partir do quinto ano, em plena produção, de nove cultivares de ameixeira (Prunus salicina) - Amarelinha, América, Harry Pickstone, Irati, Methley, Pluma 2, Pluma 7, Rosa Mineira e Reubennel - e 33 cultivares de pessegueiro (Prunus persica) - Atenas, Ametista, Ágata, Bolinha, Diamante, Eldorado, Esmeralda, Granada, Granito, Jade, Jubileu, Leonense, Maciel, Olimpia, Ônix, Pepita, Precocinho, Santa Áurea, Sensação, Turmalina, Vanguarda (de polpa amarela), Aurora 1, BR-1, BR-3, Charme, Chiripá, Chirua, Chinoca, Chula, Chimarrita, Coral, Marfim e Tropic Beauty (de polpa branca), - do Banco de Germoplasma da Embrapa Clima Temperado, Pelotas, RS ( $31^{\circ} 40^{\prime} 47^{\prime \prime} \mathrm{S}$ e $52^{\circ} 26^{\prime} 24^{\prime \prime} \mathrm{W}$; $60 \mathrm{~m}$ de altitude).

O peso de fruto e a duração do ciclo das cultivares foram avaliados em cinco safras da ameixeira (1995/1996, 1996/1997, 1997/1998, 1998/1999 e 1999/2000) e do pessegueiro (2000/2001, 2001/2002, 2002/2003, 2003/2004 e 2004/2005). Em cada safra, foram utilizados 30 frutos de 3 plantas, de cada cultivar, para obtenção do peso médio de fruto. Nas mesmas plantas, a duração do ciclo das cultivares foi calculada pelo número de dias da plena floração $(50 \%$ de flores abertas) ao início da maturação dos frutos $(10 \%$ dos frutos maduros), por estimativa visual. Utilizou-se o delineamento inteiramente casualizado, com cinco repetições (safras), e os dados foram submetidos à análise de variância, seguida pelo agrupamento de médias pelo teste de Scott-Knott, a 5\% de probabilidade, pelo programa Genes (Cruz, 2006).

As estimativas do coeficiente de repetibilidade (r), do número de medições necessárias $\left(\eta_{0}\right)$ para uma predição adequada e do coeficiente de determinação $\left(\mathrm{R}^{2}\right)$ foram obtidas pelo programa Genes (Cruz, 2006). Na estimação do coeficiente de repetibilidade foram utilizados quatro diferentes métodos: análise de variância (ANOVA); análise dos componentes principais, com base na matriz de covariâncias fenotípicas (CPCOV); análise dos componentes principais, com base na matriz de correlações (CPCOR); e análise estrutural, com base na matriz de correlações (AECOR), segundo metodologia de Cruz et al. (2004).

$\mathrm{Na}$ ANOVA, utilizou-se o modelo estatístico com dois fatores de variação (cultivar e safra), pela equação:

$$
\mathrm{Y}_{\mathrm{ij}}=\mu+\mathrm{g}_{\mathrm{i}}+\mathrm{a}_{\mathrm{j}}+\varepsilon_{\mathrm{ij}}
$$

em que $Y_{\mathrm{ij}}$ é a observação referente à i-ésima cultivar na j-ésima medição; $\mu$ é a média geral; $g_{i}$ é o efeito 
aleatório da i-ésima cultivar, sob a influência do ambiente permanente $(i=1,2, \ldots, n) ; a_{j}$ é o efeito fixo do ambiente temporário na j-ésima medição $(j=1,2, \ldots, n)$; $\varepsilon_{\mathrm{ij}}$ é o erro experimental associado à observação $Y_{\mathrm{ij}}$.

Com base nesse modelo, o coeficiente de repetibilidade é dado por:

$$
r=\frac{\operatorname{Côv}\left(Y_{i j} ; Y_{i j}\right)}{\sqrt{\hat{V}\left(Y_{i j}\right) \hat{V}\left(Y_{i j}\right)}}=\frac{\hat{\sigma}_{p}^{2}}{\hat{\sigma}^{2}+\hat{\sigma}_{p}^{2}}=\frac{Q M G-Q M R}{Q M G+(n-1) Q M R},
$$

em que: $Y_{\mathrm{ij}}$ e $\mathrm{Y}_{\mathrm{ij}}$ são as diferentes medições, realizadas no mesmo indivíduo em diferentes safras; e $\hat{\sigma}_{\mathrm{p}}^{2}$ é a proporção da variância total $\left(\hat{\sigma}^{2}\right)$ em razão da variabilidade genética, acrescida das variações proporcionadas pelos efeitos permanentes do ambiente.

No método CPCOV, a repetibilidade é dada por:

$$
\mathrm{r}=\frac{\hat{\lambda}_{1}-\hat{\sigma}_{\mathrm{Y}}^{2}}{\hat{\sigma}_{\mathrm{Y}}^{2}(\mathrm{n}-1)} \text {, em que }: \hat{\sigma}_{\mathrm{Y}}^{2}=\frac{1}{\mathrm{n}} \sum_{\mathrm{j}=1}^{\mathrm{n}} \hat{\sigma}_{\mathrm{j}}^{2}=\hat{\sigma}^{2}+\hat{\sigma}_{\mathrm{p}}^{2} \text {. }
$$

O método CPCOR apresenta o seguinte estimador do coeficiente de repetibilidade:

$$
r=\frac{\hat{\lambda}_{k}}{\sum_{j=k}^{n} \hat{\lambda}_{j}}
$$

com $(\mathrm{j}=1,2, \ldots, \mathrm{n})$, em que: $\mathrm{n}$ é o número de medições realizadas; $\hat{\lambda}_{\mathrm{k}}$ é o autovalor associado ao autovetor, cujos elementos têm o mesmo sinal e magnitudes semelhantes.

A obtenção do coeficiente de repetibilidade pelo método AECOR é possível por

$$
r=\frac{\alpha^{\prime} \hat{R} \alpha-1}{n-1}=\frac{2}{n_{(n-1)}} \sum_{j=1}^{n} \sum_{j^{\prime}=2}^{n} \hat{\rho}_{j j^{\prime}}
$$

com j<j', em que: $\hat{\rho}_{\mathrm{jj}}$ é o elemento da j-ésima linha e j'-ésima coluna da matriz $\hat{R}$.

O cálculo do número de medições necessárias para a predição do valor real $\left(\eta_{0}\right)$ foi efetuado pela fórmula:

$$
\eta_{0}=\frac{\mathrm{R}^{2}(1-\mathrm{r})}{\left(1-\mathrm{R}^{2}\right) \mathrm{r}}
$$

em que: $\mathrm{R}^{2}$ é o coeficiente de determinação preestabelecido; $\mathrm{r}$ é o coeficiente de repetibilidade obtido por um dos métodos citados acima.

O coeficiente de determinação genotípico $\left(\mathrm{R}^{2}\right)$, que representa a certeza da predição do valor real dos genótipos selecionados com base nas $\mathrm{n}$ medições realizadas, foi obtido por:

$$
\mathrm{R}^{2}=\frac{\mathrm{n} \mathrm{r}}{1+\mathrm{r}(\mathrm{n}-1)}
$$

em que: $\mathrm{n}$ é o número de medições realizadas $(\mathrm{n}=5$, neste trabalho).

\section{Resultados e Discussão}

Houve diferenças significativas entre os genótipos avaliados, para os caracteres peso de fruto e duração do ciclo, tanto para ameixeira quanto para pessegueiro, o que mostra que há variabilidade genética entre as cultivares. Isso possibilita êxito na seleção de cultivares mais promissoras para uso em cruzamentos dirigidos.

Em ameixeira, destacaram-se as cultivares Harry Pickstone e Pluma 7, com peso de fruto significativamente maior, que devem ser preferidas em cruzamentos, para aumentar o tamanho de fruto (Tabela 1). Silva et al. (2008) obtiveram peso médio de fruto inferior a $50 \mathrm{~g}$ para as 'Harry Pickstone' e 'Reubennel', em Caldas, MG. Esse valor é inferior ao encontrado nas condições de Pelotas, RS, no presente trabalho, que foi de 71,4 g na média das duas cultivares.

Tabela 1. Peso de fruto e duração do ciclo de cultivares de ameixeira, avaliados por cinco safras (1995/1996 a $1999 / 2000)^{(1)}$.

\begin{tabular}{lcc}
\hline Cultivar & $\begin{array}{c}\text { Peso de fruto } \\
(\mathrm{g})\end{array}$ & $\begin{array}{c}\text { Duração do ciclo } \\
(\text { dias })\end{array}$ \\
\hline Amarelinha & $65,6 \mathrm{~b}$ & $143,4 \mathrm{a}$ \\
América & $57,6 \mathrm{c}$ & $94,2 \mathrm{~d}$ \\
Harry Pickstone & $74,8 \mathrm{a}$ & $133,8 \mathrm{~b}$ \\
Irati & $50,4 \mathrm{c}$ & $99,2 \mathrm{~d}$ \\
Methley & $35,4 \mathrm{e}$ & $92,4 \mathrm{~d}$ \\
Pluma 2 & $52,4 \mathrm{c}$ & $119,6 \mathrm{c}$ \\
Pluma 7 & $75,8 \mathrm{a}$ & $125,0 \mathrm{c}$ \\
Rosa Mineira & $42,8 \mathrm{~d}$ & $138,4 \mathrm{a}$ \\
Reubennel & $68,0 \mathrm{~b}$ & $134,0 \mathrm{~b}$ \\
\hline CV (\%) & 9,6 & 4,5 \\
\hline (1)Médias seguidas de letras iguais, nas colunas, não diferem entre si, pelo
\end{tabular}


As cultivares América, Irati e Methley apresentaram duração do ciclo significativamente menor que as demais cultivares (<100 dias) e devem ser utilizadas em cruzamentos com o objetivo de redução do ciclo e antecipação da colheita. Pode ser indicada, inclusive, a realização de cruzamentos entre as cultivares que apresentaram maior peso de fruto e aquelas de menor ciclo, para reunir em um só genótipo essas duas características favoráveis.

Em pessegueiro, destacaram-se Santa Áurea que diferiu significativamente das demais - e outras cultivares com peso de fruto superior a $145 \mathrm{~g}$ (Ametista, Ágata, Eldorado, Granada e Maciel). Embora a maioria das cultivares com peso de fruto superior tenham apresentado também maior duração de ciclo, algumas exceções foram verificadas, como Ágata e Granada. Esta última teve o menor ciclo entre todas as cultivares. Assim, há possibilidade de reunir, em um só genótipo, as características alto peso de fruto e ciclo curto. Todavia, as demais cultivares, com ciclo inferior a 100 dias (Pepita, BR-3 e Chinoca), tiveram peso de fruto muito baixo (Tabela 2). Esse comportamento variável de relação entre peso de fruto e duração do ciclo também foi observado por Barbosa et al. (1998), em cultivares e seleções de pessegueiro e nectarineira, cultivados em pomares adensados, em São Paulo.

Os coeficientes de repetibilidade ( $\mathrm{r}$ ) ede determinação $\left(\mathrm{R}^{2}\right)$ foram altos para peso médio de fruto e duração do ciclo (Tabelas 3 e 4). Albuquerque et al. (2004) estimaram valores menores de repetibilidade do peso de fruto em pessegueiro, que foi de 0,60 na média de dois anos, pela ANOVA.

A duração do ciclo teve $\mathrm{r}$ e $\mathrm{R}^{2}$ superiores aos do caráter peso de fruto, em ambas as espécies frutíferas. Isto indica que a duração do ciclo é menos influenciada pelo ambiente, fato evidenciado também pelo menor coeficiente de variação do caráter (Tabelas 1 e 2). Embora, pela ANOVA, tenham sido obtidos valores sempre menores, não houve grandes diferenças na estimativa do coeficiente de repetibilidade entre os métodos testados.

Assim, o número de medições necessárias $\left(\eta_{0}\right)$, para se ter uma boa acurácia, é baixo, o que facilita a identificação e seleção de genótipos superiores e reduz a mão de obra e os custos para o programa de melhoramento. Considerou-se, no presente trabalho, o método de componentes principais, com base na matriz de covariâncias, indicado por vários autores (Cavalcanti et al., 2000; Negreiros et al., 2008; Nascimento Filho et al., 2009) como o mais adequado. Observou-se que, para o caráter peso de fruto de ameixeira, uma ou duas medições (anos) já são suficientes para se ter acurácia de 90 ou 95\%, respectivamente, na predição do valor real dos indivíduos (Tabela 3). Quanto ao caráter duração do ciclo, esse valor é mais baixo e, portanto, é necessária apenas uma medição. No pessegueiro, o número de medições necessárias aumenta, mas ainda continua baixo. Quanto ao peso de fruto, o $\eta_{0}$ é de

Tabela 2. Peso de fruto e duração do ciclo de cultivares de pessegueiro, avaliados por cinco safras (2000/2001 a $2004 / 2005)^{(1)}$.

\begin{tabular}{|c|c|c|}
\hline Cultivar & $\begin{array}{c}\text { Peso de fruto } \\
(\mathrm{g})\end{array}$ & $\begin{array}{c}\text { Duração do ciclo } \\
\text { (dias) }\end{array}$ \\
\hline Atenas & $100,1 \mathrm{~d}$ & $124,0 \mathrm{~d}$ \\
\hline Ametista & $154,6 b$ & $124,2 d$ \\
\hline Ágata & $155,0 \mathrm{~b}$ & $103,2 f$ \\
\hline Bolinha & $83,3 \mathrm{e}$ & $140,8 b$ \\
\hline Diamante & $95,4 d$ & $124,6 \mathrm{~d}$ \\
\hline Eldorado & $146,0 \mathrm{~b}$ & $135,6 \mathrm{~b}$ \\
\hline Esmeralda & $120,6 \mathrm{c}$ & $130,4 \mathrm{c}$ \\
\hline Granada & $153,8 b$ & $91,8 \mathrm{~g}$ \\
\hline Granito & $117,8 \mathrm{c}$ & $113,8 \mathrm{e}$ \\
\hline Jade & $128,0 \mathrm{c}$ & $128,8 \mathrm{c}$ \\
\hline Jubileu & $116,2 \mathrm{c}$ & $124,6 \mathrm{~d}$ \\
\hline Leonense & $126,2 \mathrm{c}$ & $125,4 d$ \\
\hline Maciel & $154,4 \mathrm{~b}$ & $133,4 \mathrm{c}$ \\
\hline Olimpia & $86,8 \mathrm{e}$ & $153,8 \mathrm{a}$ \\
\hline Ônix & $122,4 \mathrm{c}$ & $116,4 \mathrm{e}$ \\
\hline Pepita & $75,4 \mathrm{e}$ & $95,0 \mathrm{~g}$ \\
\hline Precocinho & $84,0 \mathrm{e}$ & $101,4 \mathrm{f}$ \\
\hline Santa Aúrea & $186,4 \mathrm{a}$ & $119,8 \mathrm{~d}$ \\
\hline Sensação & $138,4 \mathrm{c}$ & $108,8 \mathrm{e}$ \\
\hline Turmalina & $105,4 d$ & $108,6 \mathrm{e}$ \\
\hline Vanguarda & $102,0 \mathrm{~d}$ & $105,2 \mathrm{f}$ \\
\hline Aurora 1 & $76,3 \mathrm{e}$ & $114,6 \mathrm{e}$ \\
\hline BR-1 & $78,6 \mathrm{e}$ & $115,0 \mathrm{e}$ \\
\hline BR-3 & $73,6 \mathrm{e}$ & $96,4 \mathrm{~g}$ \\
\hline Charme & $102,8 \mathrm{~d}$ & $108,0 \mathrm{e}$ \\
\hline Chiripá & $107,8 \mathrm{~d}$ & $114,2 \mathrm{e}$ \\
\hline Chirua & $89,8 \mathrm{e}$ & $104,8 \mathrm{f}$ \\
\hline Chinoca & $82,2 \mathrm{e}$ & $99,4 \mathrm{f}$ \\
\hline Chula & $74,0 \mathrm{e}$ & $120,2 d$ \\
\hline Chimarrita & $111,8 \mathrm{~d}$ & $107,4 \mathrm{e}$ \\
\hline Coral & $95,4 d$ & $101,6 f$ \\
\hline Marfim & $120,2 \mathrm{c}$ & $109,8 \mathrm{e}$ \\
\hline Tropic Beauty & $86,4 \mathrm{e}$ & $111,6 \mathrm{e}$ \\
\hline $\mathrm{CV}(\%)$ & 15,9 & 5,8 \\
\hline
\end{tabular}


aproximadamente três e sete, enquanto em relação ao caráter duração do ciclo é de duas e quatro medições, para uma acurácia de 90 e $95 \%$, respectivamente (Tabela 4).

Assim, observa-se que os caracteres peso de fruto e duração do ciclo, em ameixeira e pessegueiro, têm regularidade entre as medições e podem ser empregados na seleção fenotípica simples, com perspectivas de se obter bom ganho genético no melhoramento. Em açaizeiro, Oliveira \& Fernandes (2001) também observaram que o peso médio do fruto tem alta repetibilidade e pode ser utilizado como parâmetro de seleção fenotípica para se obter bons ganhos genéticos.
Da mesma forma, a herdabilidade desses dois caracteres tende a ser alta, pois o coeficiente de repetibilidade expressa o máximo valor possível de herdabilidade no sentido amplo (Cruz et al., 2004). Souza et al. (1998) observaram que o caráter duração do ciclo, em pessegueiro, teve herdabilidade de $91 \%$, considerada muito alta, coincidente com o valor de repetibilidade (91\%). Todavia, para o peso de fruto, os mesmos autores estimaram a herdabilidade em $32 \%$, e a repetibilidade em $51 \%$, e concluíram que ocorre um moderado efeito ambiental ou efeitos genéticos não aditivos para essa característica.

O valor de repetibilidade para peso de fruto, encontrado por Souza et al. (1998), é menor em

Tabela 3. Estimativas dos coeficientes de repetibilidade (r), coeficientes de determinação $\left(\mathrm{R}^{2}\right)$ e do número de medições necessárias, com acurácia de 90 e $95 \%\left(\eta_{0}\right)$, pelos métodos de análise de variância, de componentes principais com base na matriz de covariâncias, de componentes principais com base na matriz de correlação, e de análise estrutural com base na matriz de correlação, para os caracteres peso de fruto e duração do ciclo, em cinco safras de nove cultivares de ameixeira.

\begin{tabular}{|c|c|c|c|c|}
\hline Método & $\mathrm{r}$ & $\mathrm{R}^{2}(\%)$ & $\eta_{0}(90 \%)$ & $\eta_{0}(95 \%)$ \\
\hline & \multicolumn{4}{|c|}{ Peso de fruto } \\
\hline Análise de variância & 0,8620 & 96,90 & 1,441 & 3,042 \\
\hline Componentes principais - covariância & 0,8924 & 97,64 & 1,085 & 2,291 \\
\hline Componentes principais - correlação & 0,8793 & 97,33 & 1,236 & 2,608 \\
\hline \multirow[t]{2}{*}{ Análise estrutural - correlação } & 0,8787 & 97,31 & 1,242 & 2,623 \\
\hline & \multicolumn{4}{|c|}{ Duração do ciclo } \\
\hline Análise de variância & 0,9302 & 98,5205 & 0,676 & 1,427 \\
\hline Componentes principais - covariância & 0,9368 & 98,6685 & 0,607 & 1,282 \\
\hline Componentes principais - correlação & 0,9345 & 98,6179 & 0,631 & 1,331 \\
\hline Análise estrutural - correlação & 0,9341 & 98,6097 & 0,634 & 1,34 \\
\hline
\end{tabular}

Tabela 4. Estimativas dos coeficientes de repetibilidade (r), coeficientes de determinação $\left(R^{2}\right)$ e do número de medições necessárias, com acurácia de 90 e 95\% $\left(\eta_{0}\right)$, pelos métodos de análise de variância, de componentes principais com base na matriz de covariâncias, de componentes principais com base na matriz de correlação e de análise estrutural com base na matriz de correlação, para os caracteres peso de fruto e duração do ciclo, em 5 safras de 33 cultivares de pessegueiro.

\begin{tabular}{lcccc}
\hline Método & $\mathrm{r}$ & $\mathrm{R}^{2}(\%)$ & $\eta_{0}(90 \%)$ & $\eta_{0}(95 \%)$ \\
\hline \multirow{2}{*}{ Análise de variância } & 0,7176 & 92,7032 & Peso de fruto & 7,478 \\
Componentes principais - covariância & 0,7426 & 93,5173 & 3,542 & 6,585 \\
Componentes principais - correlação & 0,7427 & 93,5207 & 3,119 & 6,582 \\
Análise estrutural - correlação & 0,7414 & 93,4790 & 3,139 & 6,627 \\
\hline \multirow{4}{*}{ Análise de variância } & 0,8049 & 95,3752 & 2,182 & 4,607 \\
Componentes principais - covariância do ciclo & 0,8390 & 96,3048 & 1,727 & 3,645 \\
Componentes principais - correlação & 0,8394 & 96,3138 & 1,722 & 3,636 \\
Análise estrutural - correlação & 0,8391 & 96,3068 & 1,726 & 3,643
\end{tabular}


comparação ao do presente trabalho. Porém, é necessário considerar que as estimativas de repetibilidade variam de acordo com: a natureza da característica avaliada; as propriedades genéticas da população; as condições em que os indivíduos se desenvolvem; e o genótipo do indivíduo em que se realizam as medidas repetidas, se esse genótipo encontrar estabilizado (Cruz et al., 2004).

No programa de melhoramento de fruteiras de caroço, da Embrapa Clima Temperado, essas características são avaliadas por, pelo menos, cinco safras consecutivas, para subsídio da seleção de parentais superiores e uso como descritores das possíveis cultivares. A partir do presente trabalho, para as características estudadas, observou-se que o número de medições pode ser reduzido, para, assim, diminuir os custos e a mão de obra necessária, sem comprometer a confiabilidade.

\section{Conclusões}

1. As cultivares de ameixeira Harry Pickstone e Pluma 7 e a cultivar de pessegueiro Santa Áurea destacam-se quanto ao maior peso de frutos, e as cultivares de ameixeira América, Irati e Methley e a cultivar de pessegueiro Granada destacam-se pela menor duração do ciclo.

2. Os coeficientes de repetibilidade e de determinação são altos, para ambos os caracteres avaliados, em ameixeira e pessegueiro.

3. Não há diferenças no coeficiente de repetibilidade entre os métodos utilizados.

4. São necessárias de uma a três medições do peso de fruto, e de uma a duas medições da duração do ciclo, para obtenção dos valores genotípicos reais das cultivares de ameixeira e pessegueiro, respectivamente.

\section{Referências}

ALBUQUERQUE, A.S.; BRUCKNER, C.H.; CRUZ, C.D.; SALOMÃO, L.C.C.; NEVES, J.C.L. Repeatability and correlations among peach physical traits. Crop Breeding and Applied Biotechnology, v.4, p.441-445, 2004.

ALVES, R.M.; RESENDE, M.D.V. de. Avaliação genética de indivíduos e progênies de cupuaçuzeiro no Estado do Pará e estimativas de parâmetros genéticos. Revista Brasileira de Fruticultura, v.30, p.696-701, 2008.
BARBOSA, W.; CAMPO DALL'ORTO, F.A.; OJIMA, M.; SANTOS, R.R. dos. O pessegueiro no sistema de pomar compacto. VIII. Caracterização de cultivares e seleções para diferentes densidades populacionais. Scientia Agricola, v.55, p.191-195, 1998.

CAVALCANTI, J.J.V.; PAIVA, J.R. de; BARROS, L. de M.; CRISÓSTOMO, J.R.; CORRÊA, M.P.F. Repetibilidade de caracteres de produção e porte da planta em clones de cajueiro-anão precoce. Pesquisa Agropecuária Brasileira, v.35, p.773-777, 2000.

COSTA, J.G. da. Estimativas de repetibilidade de alguns caracteres de produção em mangueira. Ciência Rural, v.33, p.263-266, 2003.

CRUZ, C.D. Programa Genes: biometria. Viçosa: UFV, 2006. $382 \mathrm{p}$.

CRUZ, C.D.; REGAZZI, A.J.; CARNEIRO, P.C.S. Modelos biométricos aplicados ao melhoramento genético. 3.ed. Viçosa: UFV, 2004. 480p.

DEGENHARDT, J.; DUCROQUET, J.P.; REIS, M.S. dos; GUERRA, M.P.; NODARI, R.O. Efeito de anos e determinação do coeficiente de repetibilidade de características de frutos de goiabeira-serrana. Pesquisa Agropecuária Brasileira, v.37, p.1285-1293, 2002.

FARIAS NETO, J.T. de; LINS, P.M.P.; MÜLLER, A.A. Estimativa dos coeficientes de repetibilidade para produção de fruto e albúmen sólido em coqueiro híbrido. Pesquisa Agropecuária Brasileira, v.38, p.1237-1241, 2003.

FARIAS NETO, J.T. de; YOKOMIZO, G.; BIANCHETTI, A. Coeficientes de repetibilidade genética de caracteres em pupunheira. Revista Brasileira de Fruticultura, v.24, p.731-733, 2002.

LOPES, R.; BRUCKNER, C.H.; CRUZ, C.D.; LOPES, M.T.G.; FREITAS, G.B. de. Repetibilidade de características do fruto de aceroleira. Pesquisa Agropecuária Brasileira, v.36, p.507-513, 2001.

NASCIMENTO FILHO, F.J. do; ATROCH, A.L.; CRUZ, C.D.; CARNEIRO, P.C.S. Repetibilidade da produção de sementes em clones de guaraná. Pesquisa Agropecuária Brasileira, v.44, p.605-612, 2009.

NEGREIROS, J.R. da S.; SARAIVA, L.S.; OLIVEIRA, T.K. de; ÁlVARES, V. de S.; RONCATTO, G. Estimativas de repetibilidade de caracteres de produção em laranjeiras-doces no Acre. Pesquisa Agropecuária Brasileira, v.43, p.1763-1768, 2008.

OLIVEIRA, M. do S.P. de; FERNANDES, G.L. da C. Repetibilidade de caracteres do cacho de açaizeiro nas condições de Belém-PA. Revista Brasileira de Fruticultura, v.23, p.613-616, 2001.

RASEIRA, M.C.B.; NAKASU, B.H. Melhoramento genético de fruteiras temperadas. In: NASS, L.L.; VALOIS, A.C.C.; MELO, I.S. de; VALADARES-INGLIS, M.C. (Ed.). Recursos genéticos e melhoramento - plantas. Rondonópolis: Fundação MT, 2001. p.443-477. 
SILVA, F.P.; SILVA, M. das D.D.; COSTA, A.A. da; RAMOS, J.G. de A. Desempenho produtivo de cultivares de ameixeira japonesa (Prunus salicina Lindl.), em Caldas-MG. Revista Ciência Agronômica, v.39, p.281-286, 2008.

SOARES, E.B.; GOMES, R.L.F.; CAMPELO, J.E.G.; LOPES, Â.C. de A.; MATOS FILHO, C.H.A. Repetibilidade e correlações entre caracteres morfo-agronômicos de cajazeira. Ciência e Agrotecnologia, v.32, p.1851-1857, 2008.
SOUZA, V.A.B. de; ARAÚJO, E.C.E.; VASCONCELOS, L.F.L.; LIMA, P.S. da C. Variabilidade de características físicas e químicas de frutos de germoplasma de bacuri da Região Meio-Norte do Brasil. Revista Brasileira de Fruticultura, v.23, p.677-683, 2001.

SOUZA, V.A.B. de; BYRNE, D.H.; TAYLOR, J.F. Heritability, genetic and phenotypic correlations, and predicted selection response of quantitative traits in peach. II. An analysis of several reproductive traits. Journal of the American Society for Horticultural Science, v.123, p.604-611, 1998.

Recebido em 19 de maio de 2010 e aprovado em 19 de julho de 2010 